\title{
Microstructure Modification of Yttria-Stabilized Zirconia Layers Prepared by EB-PVD
}

\author{
Norio YAMAGUCHI, Kunihiko WADA, Kazushige KIMURA and Hideaki MATSUBARA \\ Nanocoating Project Division, Materials Research and Development Laboratory, Japan Fine Ceramics Center (JFCC), \\ 2-4-1, Mutsuno, Atsuta-ku, Nagoya-shi 456-8587
}

\author{
EB-PVD 法によるイットリア安定化ジルコニア膜の微構造制御 \\ 山口哲央·和田国彦 · 木村和成 ·松原秀彰 \\ (財)ファインセラミックスセンター材料技術研究所ナノコーティングプロジェクト室, 456-8587 名古屋市熱田区六野 2-4-1
}

\begin{abstract}
Microstructures and texture of yttria-stabilized zirconia (YSZ) layers prepared by electron beam physical vapor deposition (EB-PVD) were investigated, addressing the effect of processing parameters. All the YSZ layers investigated in this study showed a columnar structure. However, significant differences were found in their microstructures. Morphology, porosity, and texture of the layers changed drastically by substrate manipulation during deposition. Without rotation, the layer showed a dense columnar structure with less intercolumnar gaps and obscure feather-like structures, and no preferred growth orientation. Rotation was very effective in developing feather-like structures within each column and hence increasing porosity. In addition, substrate rotation caused strong (100) texture. These results are attributed to the flux shadowing effect induced by oblique vapor incidence caused by substrate manipulation. The influence of electron beam power and substrate temperature was also investigated.
\end{abstract}

[Received May 30, 2003; Accepted September 30, 2003]

Key-words : EB-PVD, Zirconia, Columnar structure, Thermal barrier coating

1. Introduction

Electron beam physical vapor deposition (EB-PVD) process has currently been applied to thermal barrier coatings (TBCs) for aircraft engines. The majority of today's TBCs are based on partially yttria-stabilized zirconia (YSZ) system because of its low thermal conductivity, high melting point, relatively high thermal expansion coefficient, and good erosion resistance. Due to unique columnar structure, EB-PVD TBCs have advantages in resistances to thermal shock and thermal cycle for their applications, compared to films prepared by plasma spray (PS).1) On the other hand, EB-PVD TBCs have higher thermal conductivity, namely lower thermal barrier efficiency, than that of PS TBCs. Such characteristics are strongly related to microstructures of coatings. The cracks aligned parallel to the substrate surface, in other words, perpendicular to the direction of heat flow in films, which exist abundantly in PS films and rarely in EB-PVD films, are highly effective in lowering thermal conductivity. The most characteristic feature of EB-PVD films is columnar structure of crystalline with gap between columns (intercolumnar porosity) and finer pores and gaps in a column (intracolumnar porosity), so-called feather like structure. ${ }^{2)}$ The feather like structure leads to the excellent resistance to thermal shock and thermal cycle, because of increasing compliance of the films in the plane parallel to the substrate. Such fine structures tend to sinter easily at high temperatures, resulting in relatively low thermal stability. ${ }^{3), 4)}$

In EB-PVD process, source material is evaporated from an ingot molten by local irradiation of high power electron beam and deposited on a substrate with temperature around $1000^{\circ} \mathrm{C}$. The greatest advantage of EB-PVD process is the ability of precise control of microstructures in nanometer scale compatible with high deposition rate, because EB-PVD is deposition from high density vapor stream consisting of atoms, molecules, and clusters. To understand the microstructure evolution in EB-PVD films, so-called 'struc- tural zone model' for PVD process ${ }^{5), 6)}$ is useful, but it is not always valid, especially in the case of accompanying substrate rotation. Precise control of microstructures, for example, size, distribution, concentration and arrangement of nano-scale pores and gaps in the columns, can improve dramatically the properties of EB-PVD TBCs. Some approaches to improve the properties of TBCs by tailoring the microstructure of coating have been recently pursued..$^{7), 8}$

In this study, we investigated the effects of processing parameters of EB-PVD on the microstructure and texture of YSZ layers, in order to develop a technique for controlling the coating microstructures in nanometer level by EB-PVD that is capable of preparing high performance TBCs.

\section{Experimental}

YSZ layers were prepared by an EB-PVD equipment utilized a $150 \mathrm{~kW}$ EB gun. The equipment consists of separate chambers for loading, preheating, coating, and facilities for transferring between each chamber, manipulation and rotation of a substrate on a horizontal axis parallel to the evaporation sources. Schematic illustration of the coating chamber is shown in Fig. 1. A substrate was positioned just above an ingot. The ingot was melted and vaporized by an electron beam generated by the EB gun. The electron beam impinged directly onto the ingot and the trajectory of the beam was away from the substrate to avoid hitting against the substrate. The ingot of $63 \mathrm{~mm}$ diameter was fed into the crucible at a constant rate during deposition to ensure continuous and stable deposition. The distance between the rotational axis (substrates) and the surface of the evaporation pool was $300 \mathrm{~mm}$. Inconel 738LC plates of $55 \mathrm{~mm} \times 20$ $\mathrm{mm} \times 2.5 \mathrm{~mm}$ polished by $\# 1200$ abrasive were used as substrates. The ceramic ingots used in this study were 63 $\mathrm{mm}$ dia. $\times 172 \mathrm{~mm}$ long with nominal composition of $\mathrm{ZrO}_{2}-$ $4 \mathrm{~mol} \% \mathrm{Y}_{2} \mathrm{O}_{3}$. Deposition time was fixed at $20 \mathrm{~min}$ in all experiments. To achieve a stoichiometry of zirconia, con- 


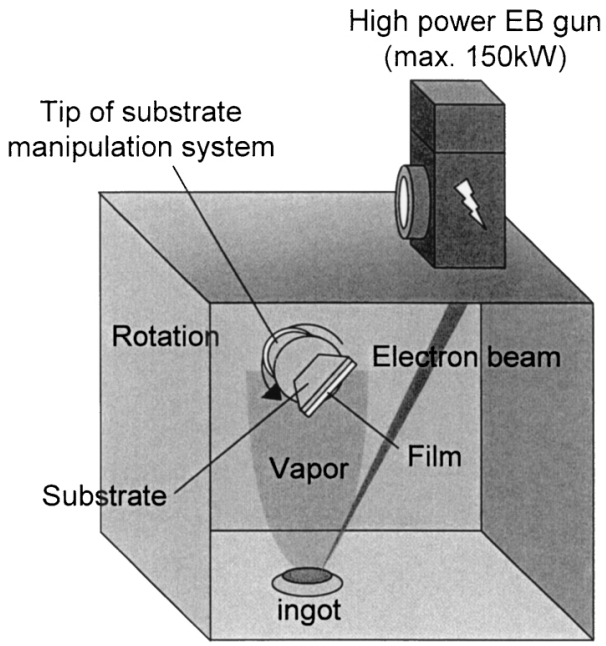

Fig. 1. Schematic illustration of the coating chamber of the EB-PVD apparatus.

trolled amount of oxygen was bled into the coating chamber and the total pressure of the coating chamber was adjusted to $1 \mathrm{~Pa}$. The substrates were preheated by radiation heating using 3 pairs of carbon heaters. The substrate temperature was measured by type- $\mathrm{N}$ thermocouples inserted in the substrate holder.

The microstructure of PVD layers is essentially determined by four basic processes: (1) shadowing, (2) surface diffusion, (3) volume diffusion and (4) desorption, which are strongly influenced by various processing parameters: substrate temperature, rotation speed, the vapor incidence angle (VIA), energy of the vapor particles, and also by chamber pressure, and deposition rate. Shadowing process is roughly described as follows: Oblique vapor flux is blocked by the column grown previously, and the region counter to the vapor flux is 'shadowed' and the vapor cannot reach there directly. If the mobility of the vapor particles on the column surface is limited, there is no growth in the shadowed region. In the line-of-sight deposition process including EB-PVD, controlling substrate manipulation is important because shadowing phenomenon is highly influenced by VIA, or substrate inclination to the vapor flow. In order to investigate the influence of substrate manipulation during deposition, YSZ layers were deposited on substrates manipulated in various manners: stationary (placing the substrate perpendicular to the vapor flow without any motion), rotation, and alternate $180^{\circ}$ rotation (rotating the substrate through $180^{\circ}$ centering around the direction of vapor flow back and forth). The rotation speed was ranged from 1 to $20 \mathrm{rpm}$ in both rotation manners. The EB power was varied from 35 to $60 \mathrm{~kW}$. In particular, for an examination of the effect of substrate manipulation, the EB power was fixed at $45 \mathrm{~kW}$. In order to maintain the substrate temperature throughout the deposition, the preheating temperature was set to the stable temperature determined mainly by radiation from the evaporation pool that is strongly dependent on the $\mathrm{EB}$ power: $850^{\circ} \mathrm{C}$ for $35 \mathrm{~kW}$, $950^{\circ} \mathrm{C}$ for $45 \mathrm{~kW}$, and $1060^{\circ} \mathrm{C}$ for $60 \mathrm{~kW}$. Table 1 summarizes the experimental conditions in this study.

Microstructures of coatings were investigated by scanning electron microscopy (SEM). Phase composition and texture were analyzed by X-ray diffraction (XRD). Porosity was calculated from weight gain of the specimens and the coating thickness measured from cross-sectional images using SEM.
Table 1. Experimental Conditions

\begin{tabular}{|l|c|c|c|c|c|c|c|}
\hline & $\begin{array}{l}\text { Stationary } \\
\text { deposition }\end{array}$ & \multicolumn{3}{|c|}{ Rotation } & \multicolumn{3}{c|}{$\begin{array}{c}\text { Alternate } 180^{\circ} \\
\text { rotation }\end{array}$} \\
\cline { 3 - 8 } & & $1 \mathrm{rpm}$ & $5 \mathrm{rpm}$ & $20 \mathrm{rpm}$ & $1 \mathrm{rpm}$ & $5 \mathrm{rpm}$ & $20 \mathrm{rpm}$ \\
\hline $35 \mathrm{~kW}$ & & & $\bigcirc$ & & & & \\
\hline $45 \mathrm{~kW}$ & $\bigcirc$ & & $\bigcirc$ & $\bigcirc$ & & $\bigcirc$ & $\bigcirc$ \\
\hline $60 \mathrm{~kW}$ & & & $\bigcirc$ & & & & \\
\hline
\end{tabular}

\section{Results and discussion}

3.1 Microstructure, morphology and texture of YSZ layers

Figure 2 shows fractured cross-sectional images of YSZ layers deposited under various conditions. All the layers exhibited columnar structures, but significant differences exist between stationary deposited layer and layers deposited with substrate manipulation. The stationary deposited layer is dense with less porosity between columns, and the feather-like structure is obscure. The rotationally deposited layers exhibited wider intercolumnar gaps and more apparent feather-like structures. At low rotational speed, typically at $1 \mathrm{rpm}$, layered structures of bent columns are clearly seen, similar to many literatures. ${ }^{9), 10)} \mathrm{C}$-shaped structure (Fig. 3(a)) and s-shaped structure (Fig. 3(b)) are formed on rotated substrates and on alternately $180^{\circ}$ rotated ones, respectively. Such layered structures were more pronounced close to the substrate and the periodicity of the bent layers was corresponding to the rotational speed. These structures can be explained by the continuous change of the VIA during rotation and periodical facing and interrupting of the vapor flux to the substrate. In the case of low rotation speed, the amount of vapor particles adhered on the growing surface at each VIA is relatively large, and the continuous change of VIA lead to formation of apparent bent columns. The actual growth direction of columns closely follows the change of VIA, because EB-PVD is line-of-sight deposition process. When rotational direction is the same during deposition, c-shaped columns are formed. In alternate $180^{\circ}$ rotation, rotational direction changes alternately, so s-shaped bent columns are formed. With increasing rotational speed, the columns show straight morphology with less striation, as seen in the layers deposited at $20 \mathrm{rpm}$ (Figs. $2(\mathrm{~d})$ and $(\mathrm{g})$ ). Faster rotation reduces the amount of vapor particles arrived at the growing column top dwelled at each VIA and therefore interval of each c-shape becomes shorter resulting in straight morphology.

Figure 4 shows an effect of the substrate manipulation on the deposition rate and the porosity. Under stationary deposition conditions, the deposition rate was $10 \mu \mathrm{m} / \mathrm{min}$. Substrate rotation and alternate $180^{\circ}$ rotation decreased the deposition rates to approximately 4 and $7 \mu \mathrm{m} / \mathrm{min}$, respectively. Under stationary deposition condition, the substrate was always exposed to the vapor flux with normal incidence. Under rotation, on the other hand, VIA changes continuously and the impinging vapor flux was interrupted when the substrates faced away to the evaporation pool, because EB-PVD is line-of-sight deposition process. Therefore, substrate rotation decreases deposition rate. During alternate $180^{\circ}$ rotation, the substrates are always exposed to the vapor stream, differing from rotation. However, alternate $180^{\circ}$ rotation accompanies a period of oblique vapor incidence, which reduces the deposition rate. Therefore, the deposition rate also decreased under alternate $180^{\circ}$ rotation, and reduction in deposition rate in alternate $180^{\circ}$ rotation is lower than that with rotation. The porosity of the stationary deposited layer was only $7 \%$, while substrate rotation and 

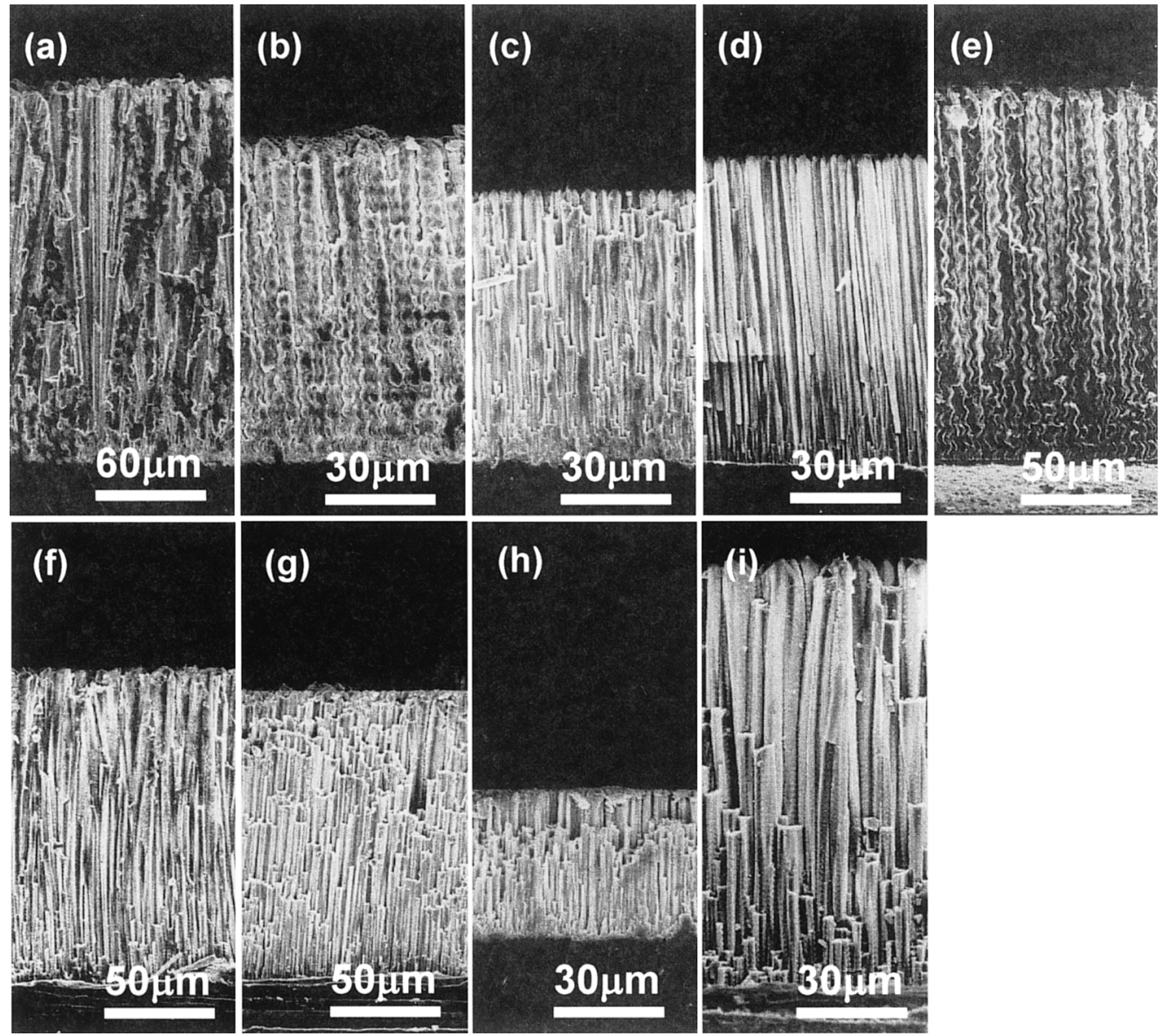

Fig. 2. Cross-sectional SEM images of YSZ layers deposited under various conditions: (a) $45 \mathrm{~kW}$, stationary condition, (b) $45 \mathrm{~kW}$, rotation at $1 \mathrm{rpm}$, (c) $45 \mathrm{~kW}$, rotation at $5 \mathrm{rpm}$, (d) $45 \mathrm{~kW}$, rotation at $20 \mathrm{rpm}$, (e) $45 \mathrm{~kW}$, alternate $180^{\circ}$ rotation at $1 \mathrm{rpm}$, (f) $45 \mathrm{~kW}$, alternate $180^{\circ}$ rotation at $5 \mathrm{rpm},(\mathrm{g}) 45 \mathrm{~kW}$, alternate $180^{\circ}$ rotation at $20 \mathrm{rpm},(\mathrm{h}) 35 \mathrm{~kW}$, rotation at $5 \mathrm{rpm}$, (i) $60 \mathrm{~kW}$, rotation at $5 \mathrm{rpm}$.

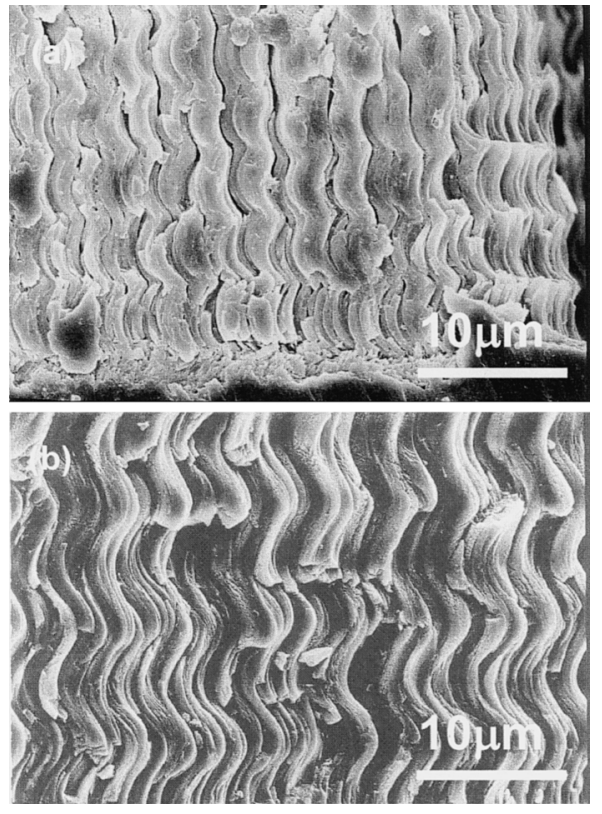

Fig. 3. Higher magnification image of bent columns: (a) rotation, $1 \mathrm{rpm}$, (b) alternate $180^{\circ}$ rotation, $1 \mathrm{rpm}$.

alternate $180^{\circ}$ rotation caused rapid increase of porosity, up to over $20 \%$. This is related to change of microstructure, especially development of the feather-like structure, which will be discussed later. Intracolumnar nano-pores are likely to increase with raising rotational speed, because faster rotation is expected to increase scattering of vapor species leading to a more randomized coating flux, and thus, collisions of evaporated species in the vapor flow, resulting in formation of clusters. The clusters would impinge on the growing surface to form mounds. Continuous impingement of clusters makes it difficult for the mounded clusters to relax their structure fully and they cannot fill gaps between mounds. Therefore, nano-pores are easily introduced in columns by deposition from clusters.

Deposition rate and porosity as a function of the EB power are shown in Fig. 5. As the EB power increases, the deposition rate increased linearly from $1.6 \mu \mathrm{m} / \mathrm{min}$ at 35 $\mathrm{kW}$ to $7.2 \mu \mathrm{m} / \mathrm{min}$ at $60 \mathrm{~kW}$. Increasing $\mathrm{EB}$ power raised the evaporation rate due to increasing energy input to the ingot. The evaporation rate is almost equivalent to the consumption rate of the ingot, in other words, the ingot feed rate. In fact, the ingot feed rate was increased also linearly from $0.5 \mathrm{~mm} / \mathrm{min}$ at $35 \mathrm{~kW}$ to $1.5 \mathrm{~mm} / \mathrm{min}$ at $60 \mathrm{~kW}$ to continue stable evaporation. In this $\mathrm{EB}$ power range, raising $\mathrm{EB}$ power is expected to increase the evaporation rate linearly, which results in linear increase in the deposition rate. Porosity showed a maximum around $45 \mathrm{~kW}$. High EB power promotes the evaporation of the source material and the density of vapor species is raised as a result. Therefore, the probability of cluster formation increases in the vapor stream leading to increasing intracolumnar pores. At the 


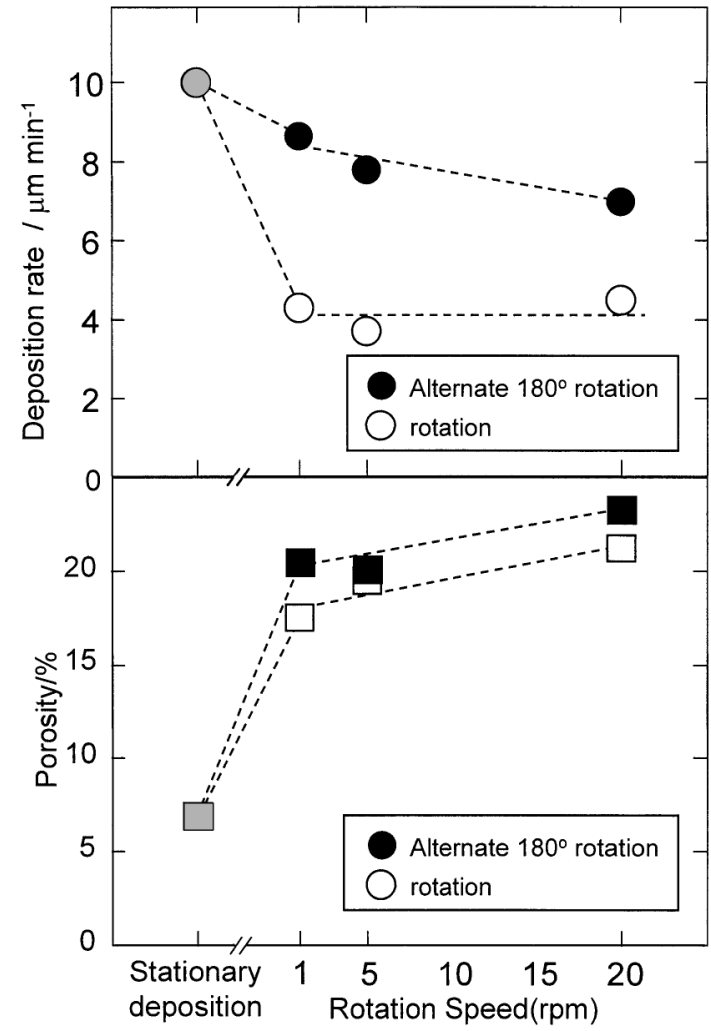

Fig. 4. Effect of substrate motions on deposition rate and porosity of YSZ layers.

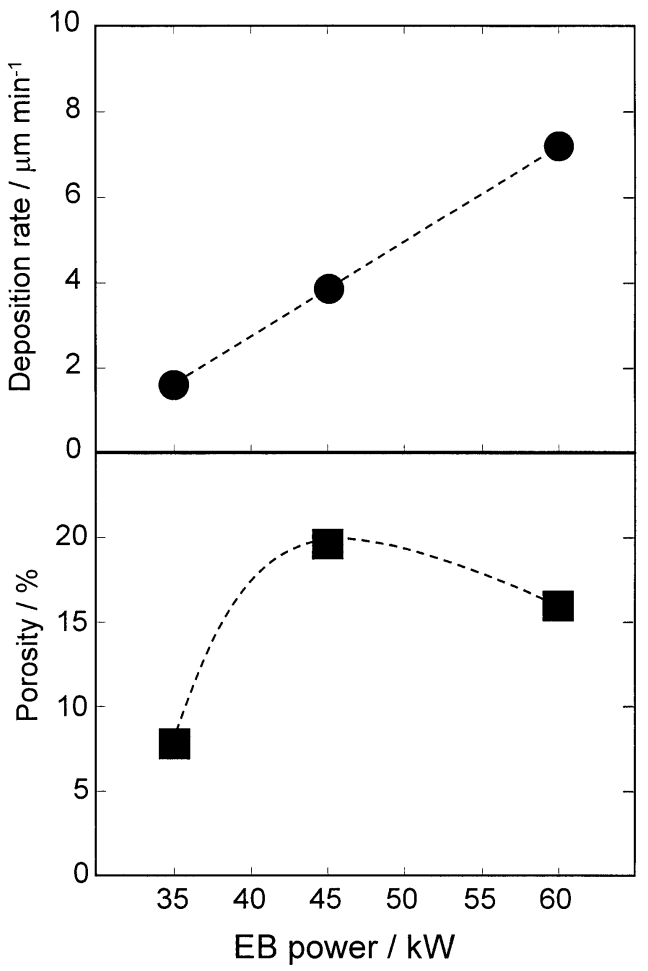

Fig. 5. Deposition rate and porosity as a function of the electron beam power.

same time, however, the increase in the EB power also causes raising substrate temperature because radiation

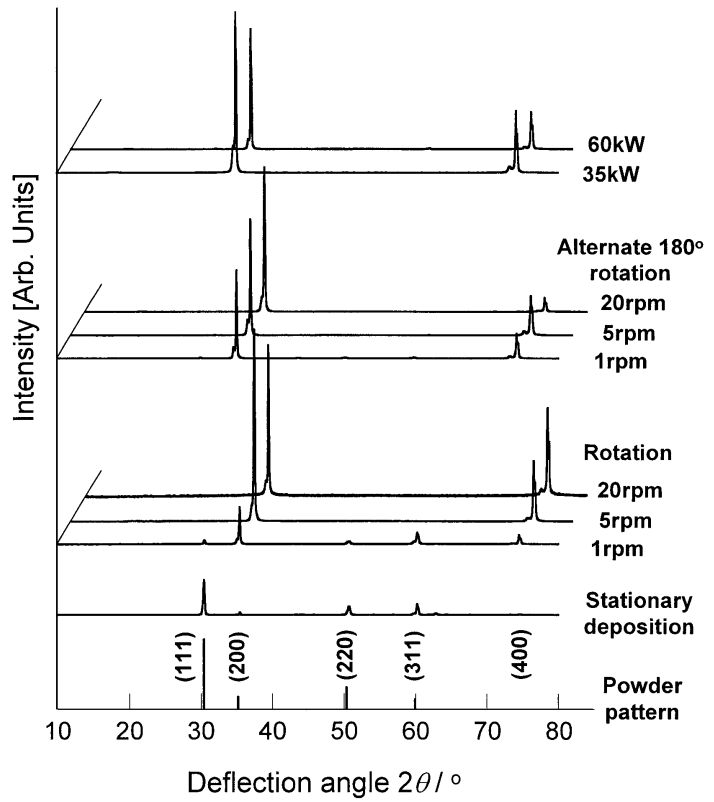

Fig. 6. XRD patterns of YSZ layers deposited under various conditions.

from the evaporation pool becomes strong. The high substrate temperature promotes surface diffusion of impinged particles and makes column width thicker, and then the sum of surface area of columns decreases. Nano-pores and nanogaps related to the feather-like structure usually exist near the surface of columns, so they probably decrease with increasing substrate temperature. In addition, very high substrate temperature may promote sintering within columns, resulting in decrease in intracolumnar nano-pores. Porosity is likely to be determined by balance of the phenomena described above. Therefore, porosity shows a maximum at moderate EB power.

XRD patterns of the YSZ layers are shown in Fig. 6. Peak splits, typically between $73^{\circ}$ to $75^{\circ}$, are clearly evident and are attributed to the presence of the metastable tetragonal $t^{\prime}$ phase reported in EB-PVD YSZ coatings. ${ }^{11), 12)}$ Texture of the YSZ layers showed drastic difference between the stationary deposited layer and the rotationally deposited ones. The XRD pattern of the stationary deposited layer was similar to that of the powder reference, which means no preferential growth orientation. On the contrary, strong (100) texture appears in rotationally deposited coatings, similar to that is consistent with observations made on EB-PVD YSZ coatings. ${ }^{13), 14)}$ This is because shadowing effect is much more pronounced over the rotating substrate. Anisotropy of growth and diffusion coefficients leads to the dominance of columns with fastest growth rates at the expense of shadowed columns that are growing more slowly. Under the deposition conditions in this study, (100) is thought to be the fastest growth orientation, therefore (100) oriented grains ultimately shadow and extinguish the growth of crystallites with other growth directions. As a result, rotationally deposited coatings exhibit strong (100) preferential growth orientation. At high deposition rate, even slight difference in growth rates can promote this selection of preferential oriented column, without the aid of etching by ion bombardment that has been reported in IBAD YSZ films with low deposition rate. ${ }^{15)}$

Surface morphology is also strongly influenced by the processing parameters, as shown in Fig. 7. The stationary deposited layer exhibits a mixture of flat, triangular grains 

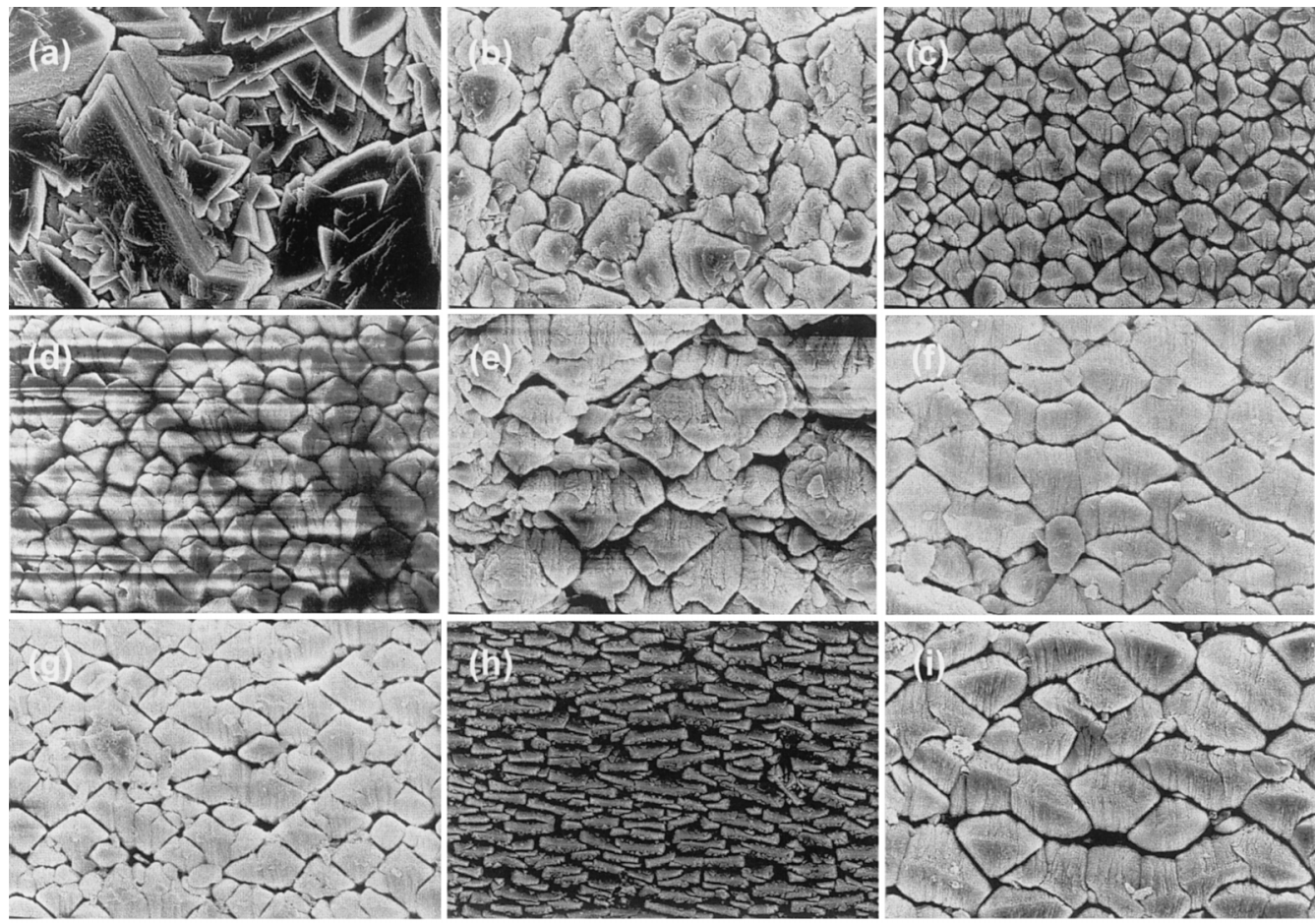

$10 \mu \mathrm{m}$

Fig. 7. Surface morphology of YSZ layers deposited under various conditions: (a) $45 \mathrm{~kW}$, stationary condition, (b) $45 \mathrm{~kW}$, rotation at $1 \mathrm{rpm}$, (c) $45 \mathrm{~kW}$, rotation at $5 \mathrm{rpm}$, (d) $45 \mathrm{~kW}$, rotation at $20 \mathrm{rpm}$, (e) $45 \mathrm{~kW}$, alternate $180^{\circ}$ rotation at $1 \mathrm{rpm}$, (f) $45 \mathrm{~kW}$, alternate $180^{\circ}$ rotation at $5 \mathrm{rpm},(\mathrm{g}) 45 \mathrm{~kW}$, alternate $180^{\circ}$ rotation at $20 \mathrm{rpm}$, (h) $35 \mathrm{~kW}$, rotation at $5 \mathrm{rpm}$, (i) $60 \mathrm{~kW}$, rotation at $5 \mathrm{rpm}$.

and grains with rooftop morphology (Fig. 7 (a)). The layers deposited with rotation shows pyramidal morphology that looks like octahedral planes on crystals of cubic symmetry. This morphology becomes irregular at low rotation speed. This difference in morphology probably reflects on the texture of the layers. Surface morphology of the layer deposited at $35 \mathrm{~kW}$ differed significantly from others. Regardless of the EB power, the layers exhibit strong (100) texture. At $35 \mathrm{~kW}$ (substrate temperature of $850^{\circ} \mathrm{C}$ ), top of the each column exhibits a rectangular rooftop shape elongated parallel to the rotational axis (Fig. $7(\mathrm{~h})$ ). Pyramidal shape column top is observed in coatings deposited at $45 \mathrm{~kW}$ (Fig. 7(c)) and at $60 \mathrm{~kW}$ (Fig. 7(i)). Rotation of substrates produces the shadowing effect of vapor flux, which is more apparent mainly in the direction perpendicular to the rotational axis. In addition, low substrate temperature at low EB power makes the nucleation density higher and the distance between neighboring columns becomes shorter and in-plane growth of columnar grains is easier in the direction parallel to the rotational axis. Surface energy and growth rate of crystallographic planes are affected by substrate temperature. Therefore, the top surface of the layer deposited at $35 \mathrm{~kW}$ shows rectangular rooftop shapes elongated along the rotation axis.

\subsection{Development of feather-like structure}

Figures 8 and 9 show detailed cross-sectional images of YSZ layers deposited without and with rotation, respectively. Their structures are quite different from each other. The stationary deposited layer shows dense, highly tapered columnar structure, because columns grow by a competitive growth mechanism. The rotationally deposited layer exhibits much less tapered columnar structure with wider intercolumnar gaps and feather like structure is much more pronounced.
Figures $10(\mathrm{a})$ and (b) show polished cross-sectional images of YSZ layers. These images indicate that the columnar grains are separated by gaps in submicrometer scale and each grain consists of a dense core with a few nano-pores, micro-columns on the column surface aligned nearly parallel to each other, and elongated nano-pores and nano-gaps between micro-columns.

Figure 11 shows a schematic illustration of the microstructure of YSZ layer produced by EB-PVD. This characteristic is strongly influenced by shadowing process. Shadowing process is described as follows: vapor flux incident obliquely on the growing surface is blocked by the previously deposited film material, and the region counter to the vapor flux is 'shadowed' and the vapor cannot reach the shadowed regions directly. If the mobility of the vapor particles on the surface is limited, there is no growth in the shadowed regions. As a result, the grains tend to grow toward the direction of vapor incidence and exhibit columnar structure. Rotational motion makes the columns perpendicular to the substrate surface as a whole, because the VIA ranging from $-90^{\circ}$ to $+90^{\circ}$ changes continuously. Shadowing occurs not only between the main columns but also between finer microstructures within the main columns. During deposition, a number of islands separated by nanoscale gaps are growing on the terminal surface of the main columns. Nano-scale gaps between such islands cause shadowing on nanometer scale, which is closely related to formation of intracolumnar nano-pores and 'micro-columns' on the main columns. We classify the shadowing phenomena into two types: type I, intercolumnar shadowing on micrometer scale, which mainly governs columnar growth, and type II, intracolumnar shadowing on nanometer scale, which closely concerns a formation of the feather-like structure. Development of the feather-like structures could be 


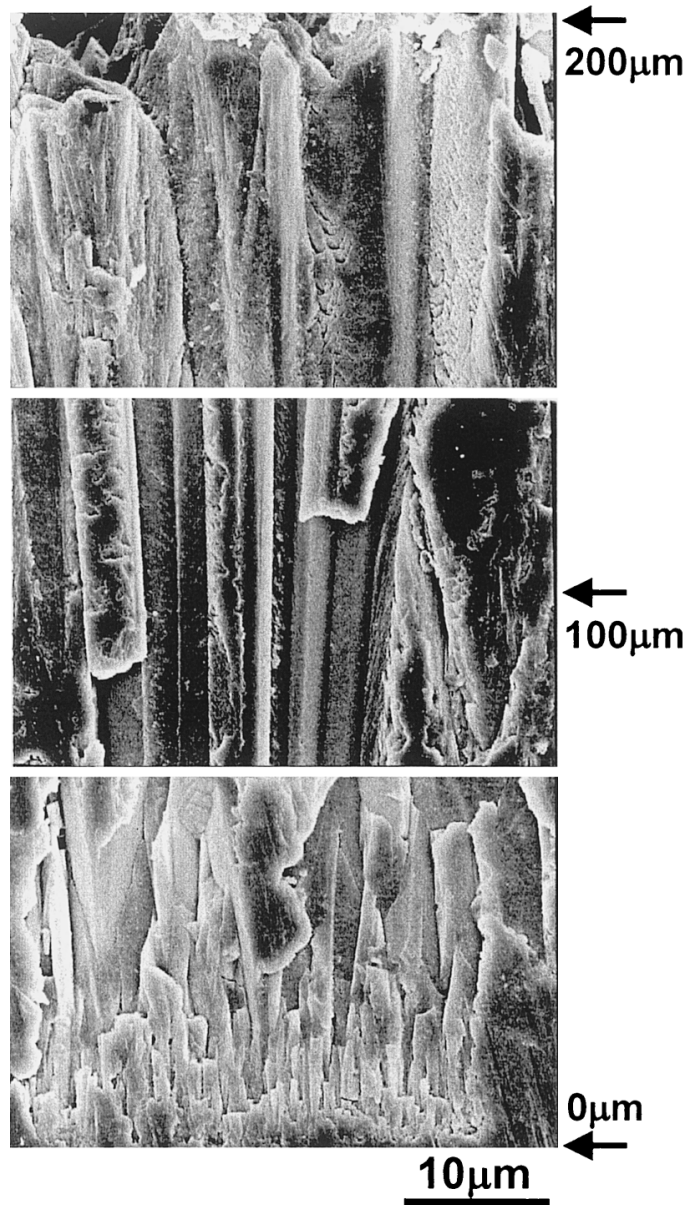

Fig. 8. Detailed cross-sectional image of the YSZ layer deposited at $45 \mathrm{~kW}$, stationary deposition.

also treated in close analogy to macroscopic columnar formation described in the classical structure zone models for PVD coatings. ${ }^{3), 4)}$ Shadowing by the main columns and surface diffusion of the adhered particles cause the structural evolution of the micro-columns. The edge of the main columns interrupts the majority of the flux and produces a shadow, but there is small fraction of vapor particles that can penetrate the intercolumnar gaps and impinge on the main column side at a locally high VIA. In addition, the intercolumnar gaps have a collimating effect on vapor flux resulting in limitation of an angular distribution of the flux, which leads to formation of well-aligned micro-columns on the main columns that produce the feather-like appearance. In recent investigation, columnar YSZ layer with featherlike structure was also formed on a stationary substrate inclined to the vapor stream without rotation. ${ }^{16)}$ This result confirmed that shadowing effect is strongly related to oblique vapor incidence. The shadowing of vapor flux by the columns caused by substrate rotation takes place mainly in the direction perpendicular to the rotation axis, so the feather-like structures seem to be more apparent in the column side perpendicular to the rotation axis than that parallel to the axis.

As mentioned above, microstructure and texture of the EB-PVD films are strongly influenced by the shadowing of the vapor flux by columnar grains that depends on VIA, which is closely related to substrate alignment to vapor stream. Since EB-PVD is the line-of-sight deposition process, the substrate manipulation, which can control the

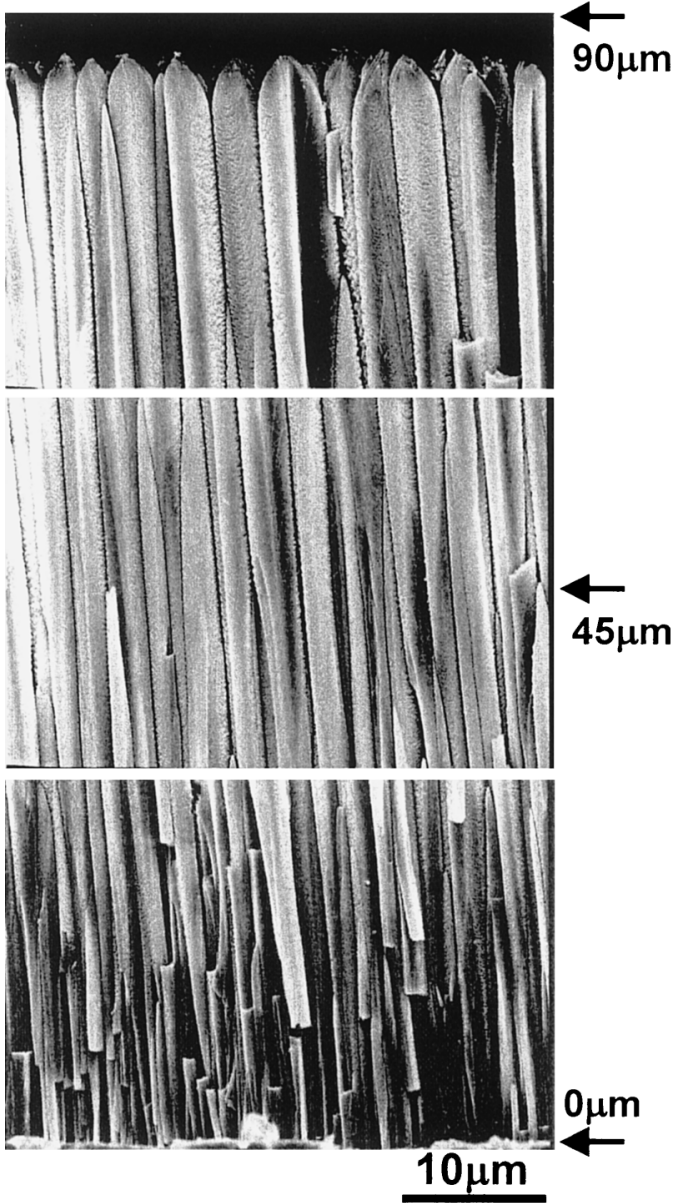

Fig. 9. Detailed cross-sectional image of the YSZ layer deposited at $45 \mathrm{~kW}$, rotation at $20 \mathrm{rpm}$.

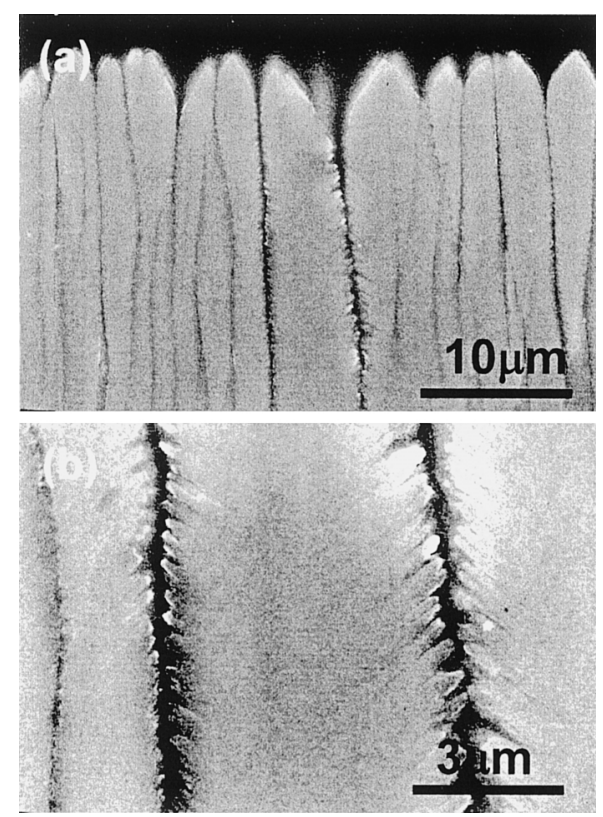

Fig. 10. (a) Polished cross-sectional SEM images of the YSZ layer near the top surface, (b) higher magnification of (a).

VIA and thus the shadowing effect, is one of the most important parameters for controlling microstructures. 


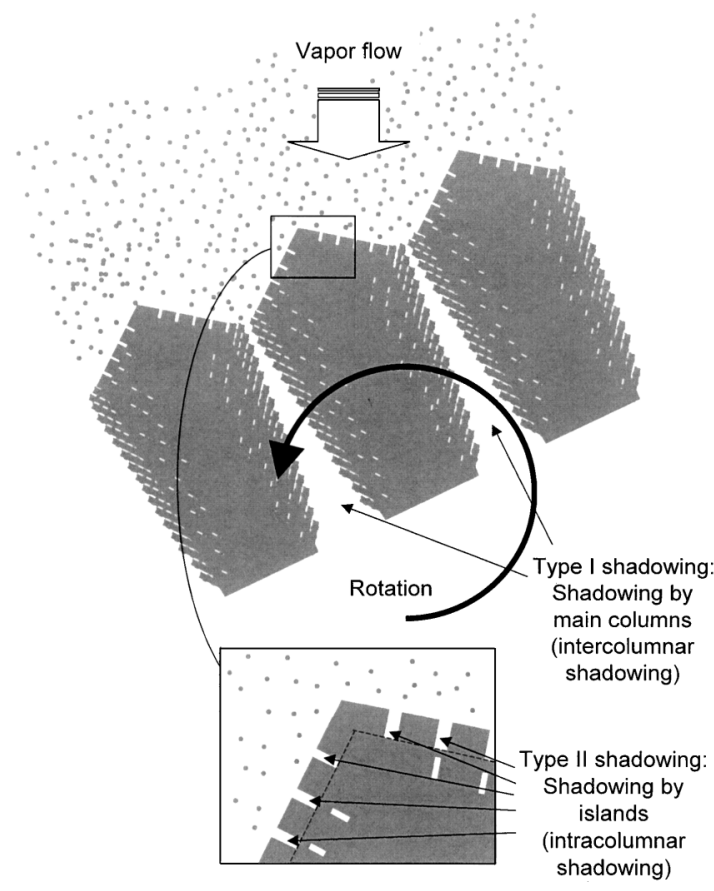

Fig. 11. Schematic illustration of the microstructure of the YSZ layer prepared by EB-PVD. This structure is strongly influenced by two types of shadowing processes.

\section{Conclusion}

Microstructure of yttria stabilized zirconia layers prepared by electron beam physical vapor deposition was investigated, focusing on the effect of processing parameters. All the YSZ layers showed a columnar structure, but the microstructure and texture strongly depend on deposition conditions, especially on substrate manipulation. Stationary deposited layer showed a dense columnar structure with less intercolumnar gaps and obscure feather-like structures, and no preferred growth orientation. Rotationally deposited layers showed well-developed feather-like structures within each column and hence increasing porosity. Substrate rotation also influenced on the texture of the layers resulting in highly (100) orientation. The electron beam power also influenced the microstructure, especially the surface morphology. These results are attributed to the flux shadowing effect induced by oblique vapor incidence caused by substrate manipulation. Substrate manipulation is one of the most effective methods for controlling morphology in EB-PVD process.

Acknowledgment This work was entrusted by NEDO as "the Nanotechnology Materials Program/the Nanostructure Coating Project" promoted by METI, Japan.

\section{References}

1) Peters, M., Leyens, C., Schulz, U. and Kaysser, W. A., Adv. Eng. Mater., Vol. 3, pp. 193-204 (2001).

2) Schulz, U., Fritscher, K. and Leyens, C., Surf. Coat. Technol., Vol. 133-134, pp. 40-48 (2000).

3) Stiger, M. J., Yanar, N. M., Topping, M. G., Pettit, F. S. and Meier, G. H., Z. Metallkd, Vol. 90, pp. 1069-1078 (1999).

4) Leyens, C., Schulz, U., Fritscher, K., Bartsch, M., Peters, M. and Kaysser, W. A., Z. Metallkd, Vol. 92, pp. 762-772 (2001).

5) Movchan, B. A. and Demchishin, A. V., Phys. Met. Metallogr., Vol. 28, pp. 83-90 (1969).

6) Thornton, J. A., Ann. Rev. Mater. Sci., Vol. 7, pp. 239-260 (1977).

7) Hass, D. D., Slifka, A. J. and Wadley, H. N. G., Acta mater., Vol. 49, pp. 973-983 (2001).

8) Nicholls, J. R., Lawson, K. J., Johnstone, A. and Rickerby, D. S., Surf. Coat. Technol., Vol. 151-152, pp. 383-391 (2002).

9) Rigney, D. V., Viguie, R., Wortman, D. J. and Skelly, D. W., NASA Conference 3312, pp. 135-149 (1995).

10) Schulz, U. and Schmücker, M., Mater. Sci. Eng., Vol. A276, pp. 1-8 (2000).

11) Schulz, U., Fritscher, K. and Peters, M., Surf. Coat. Technol., Vol. 82, pp. 259-269 (1996).

12) Hass, D. D., Parrish, P. A. and Wadley, H. N. G., J. Vac. Sci. Technol., Vol. A16, pp. 3396-3401 (1998).

13) Unal, O., Mitchell, T. E. and Heuer, A. H., J. Am. Ceram. Soc., Vol. 77, pp. 984-992 (1994).

14) Schulz, U., Oettel, H. and Bunk, W., Z. Metallkd, Vol. 87, pp. 488-492 (1996).

15) Sonnenberg, N., Longo, A. S., Cima, M. J., Chang, B. P., Ressler, K. G., Mclntyre, P. C. and Liu, Y. P., J. Appl. Phys., Vol. 74, pp. 1027-1034 (1993).

16) Terry, S. G., Litty, J. R. and Levi, C. G., "Elevated Temperature Coatings: Science and Technology III," Ed. by Hampikan, J. M. and Dahotre, N. B., Minerals, Metals \& Materials Society (1999) pp. 13-26. 